\title{
A comparative study on the location of the mandibular foramen in CBCT of normal occlusion and skeletal class II and III malocclusion
}

Hae-Seo Park and Jae-Hoon Lee*

\begin{abstract}
Background: During the orthognathic surgery, it is important to know the exact anatomical location of the mandibular foramen to achieve successful anesthesia of inferior alveolar nerve and to prevent damage to the nerves and vessels supplying the mandible.

Methods: Cone-beam computed tomography (CBCT) was used to determine the location of the mandibular foramen in 100 patients: 30 patients with normal occlusion (13 men, 17 women), 40 patients with skeletal class II malocclusion (15 men, 25 women), 30 patients with skeletal class III malocclusion (17 men, 13 women).

Results: The distance from the anterior border of the mandibular ramus to mandibular foramen did not differ significantly among the three groups, but in the group with skeletal class III malocclusion, this distance was an average of $1.43 \pm 1.95 \mathrm{~mm}$ longer in the men than in the women $(p<0.05)$. In the skeletal class III malocclusion group, the mandibular foramen was higher than in the other two groups and was an average of $1.85 \pm 3.23 \mathrm{~mm}$ higher in the men than in the women for all three groups combined $(p<0.05)$. The diameter of the ramus did not differ significantly among the three groups but was an average of $1.03 \pm 2.58 \mathrm{~mm}$ wider in the men than in the women for all three groups combined $(p<0.05)$. In the skeletal class III malocclusion group, the ramus was longer than in the other groups and was an average of $7.9 \pm 3.66 \mathrm{~mm}$ longer in the men than women.

Conclusions: The location of the mandibular foramen was higher in the skeletal class III malocclusion group than in the other two groups, possibly because the ramus itself was longer in this group. This information should improve the success rate for inferior alveolar nerve anesthesia and decrease the complications that attend orthognathic surgery.
\end{abstract}

\section{Background}

The mandibular foramen is located inside the mandibular ramus and serves as a passageway for blood vessels that supply nutrients to the mandible, mandibular teeth, periodontal tissues, and lower lip and for the nerves responsible for sensory perception in these regions. Thus, locating the accurate anatomical position of these regions is critical to achieving more successful inferior alveolar nerve block and preventing the complications common to orthognathic surgery [1].

Inferior alveolar nerve block anesthesia is intended to reduce pain during surgery (e.g., for tooth extractions

\footnotetext{
* Correspondence: Lee201@dku.edu

First author: Hae-Seo Park

Department of Oral and Maxillofacial Surgery, College of Dentistry, Dankook University, 119 Dandae-ro, Dongnam-gu, Cheonan 330-714, Korea
}

and implantations in the mandible). The anesthetic is delivered right above the mandibular foramen, and the effect is often inadequate if the surgeon does not accurately identify the anatomical site of the foramen or if it has been dislocated [2]. In addition, orthognathic surgery intended to correct maxillofacial deformities or for aesthetic reasons may result in complications (e.g., damage to inferior alveolar nerve and local blood vessels) unless the foramen can be located precisely [3].

Radiographic images are obtained clinically to identify the position of the mandibular foramen. Although the panoramic view can be used for this purpose, it has the disadvantage of being less accurate owing to phase transformations and magnification. Computed tomography $(\mathrm{CT})$ can accurately identify the position of the foramen three-dimensionally but is expensive and

\section{Springer}


exposes the patient to an excessive dose of radiation. The recent introduction of cone-beam computed tomography $(\mathrm{CBCT})$ has overcome such disadvantages, acquiring images through a one-time rotation $[4,5]$ at a lower cost, a lower dose and with easier operation, as compared with conventional multislice CT $[4,6,7]$.

Many studies have been carried out to determine the best method for locating the mandibular foramen. Alves et al. [8] analyzed its anatomical position by measuring the mandible (in 185 cases), and da Fontoura et al. [9] determined its position in dry mandibles (in 140 cases) and compared the findings with those obtained on panoramic views. Trost et al. [10] examined the mandible (in 46 cases) to determine the relative positions of the mandibular ramus and the mandibular foramen, and Seo et al. [11] used panoramic radiography to compare differences in the position of the mandibular foramen between patients with normal occlusion and those with mandibular prognathism.

Nevertheless, few studies have compared the anatomical position of the mandibular foramen in patients with skeletal class II and class III malocclusions for whom orthognathic surgery is often performed. In this study, CBCT, which is now in wide clinical use, was chosen to compare the anterior-posterior position and vertical positions of the mandibular foramen among patients with normal occlusion and those with skeletal class II or III malocclusions.

\section{Methods}

\section{Study subjects}

The study included 100 patients who visited the Dankook University Dental Hospital from January 2013 to June 2014. Cephalometric analysis provided A point-nasion-B point (ANB) values that were used to classify the patients into three groups: 30 with normal occlusion, 40 with skeletal class II malocclusion, and 30 with skeletal class III malocclusion. Subjects was 18 to 31 years of age as of the dates when the $\mathrm{CBCT}$ radiographs were obtained. Included in the skeletal class II group were 30 patients in division 1 and 10 patients in division 2 of this class. Patients who underwent orthognathic surgery and had facial asymmetry were excluded.

\section{Study methods \\ CBCT}

CBCT radiographs taken using PHT-60FO (VATECH Corp., Hwa-Sung, Korea) were reconstructed in a panoramic view using Invivo 5.1 (Anatomage, San Jose, CA, USA). Analysis of the mandibular foramen was on the region where the mandibular canal ended.

\section{CBCT analysis}

The mandibular foramen (MF) was set posterosuperior to the opening of mandibular canal. The deepest point of the anterior edge of the mandibular ramus was named 'a' and the lowest point of mandibular notch was named 's'. The extension of the occlusal plane connecting the mesioocclusal line angle of the first premolars and the posteroocclusal line angle of the second molars was given a value of 'l' and used as a reference in comparing the positions of the mandibular foramen (Table 1, Fig. 1).

To compare the anterior and posterior positions of mandibular foramen, the distance ( $\mathrm{D}$, in $\mathrm{mm}$ ) between ' $\mathrm{a}$ ' and the MF and the shortest distance (W, in $\mathrm{mm}$ ) between ' $a$ ' and the posterior border of mandibular ramus were measured. To compare the vertical position of the mandibular foramen, the length $(\mathrm{V}$, in $\mathrm{mm})$ between ' $\mathrm{s}$ ' and the MF and the length of the perpendicular line $(\mathrm{P}$, in $\mathrm{mm})$ from the extension of occlusal plane to the MF and the shortest distance ( $R$, in $\mathrm{mm}$ ) between ' $\mathrm{s}$ ' and the inferior edge of the mandible was measured (Table 2, Fig. 2).

\section{Evaluation techniques}

In $\mathrm{CBCT}$ images reconstructed in a panoramic view, items were measured in the mandibular ramus on both sides. First, the measurements were made in the three groups of patients (those with normal occlusion, those with skeletal class II malocclusion, and those with skeletal class III malocclusion). Next, same-gender comparisons were made among the three groups. Men and women within the same group were compared, followed by a comparison between male and female patients in the entire cohort. Finally, within the skeletal class II malocclusion group, the two subsets of patients in division 1 and division 2 were compared.

\section{Statistical analysis}

When the subject of a comparison was included in all three groups, a one-way analysis of variance (ANOVA) test was conducted, followed by the Tukey test to verify the results. When the subject of a comparison included in two of the patient groups, an independent sample $t$ test was performed. Differences were considered statistically significant if the $p$ value was less than 0.05 .

\section{Results}

CBCT images of the patients in the three study groups (normal occlusion, skeletal class II malocclusion, and skeletal class III malocclusion) were compared with

Table 1 Reference point and line

\begin{tabular}{ll}
\hline MF & Posteriorsuperior point of mandibular canal opening \\
a & Deepest point on anterior border of ascending ramus \\
$s$ & Lowest point of mandibular notch \\
\hline & Extension line of occlusal plane \\
\hline
\end{tabular}




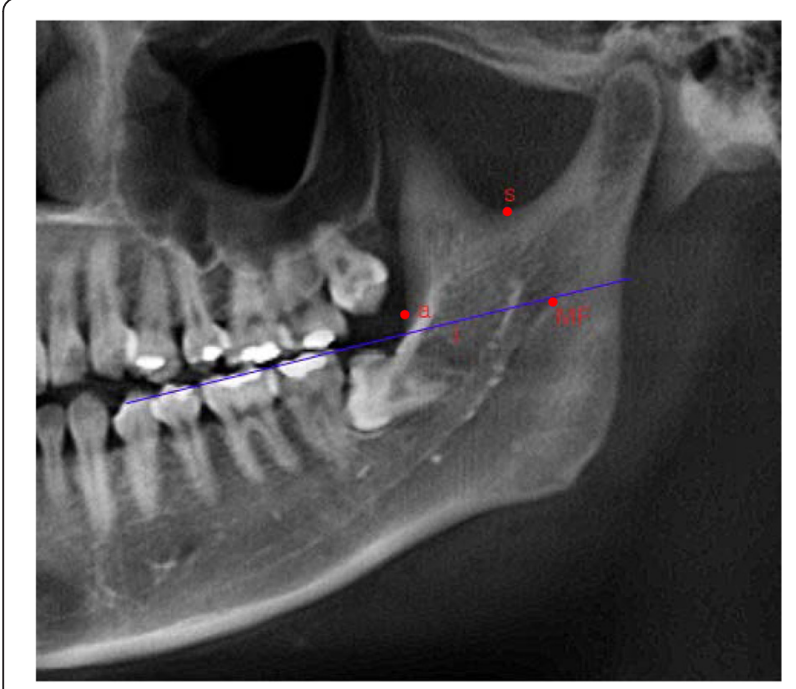

Fig. 1 Reference point and line

respect to the position of the mandibular foramen. The findings are summarized as follows.

\section{Patient groups}

Of the 100 patients, 45 patients were men and 55 were women, with a mean age of $21.5 \pm 3.2$ years. Of the 30 patients with normal occlusion, 13 were men and 17 were women, with a mean age was $21.8 \pm 3.4$ years. The average sella-nasion-A point angle (SNA) was $83.05^{\circ}$, the average sella-nasion-B point angle (SNB) was $80.22^{\circ}$, and the ANB averaged $2.83^{\circ}$. Of the 40 patients with skeletal class II malocclusion, 15 were men and 25 were women, with a mean age of $22.2 \pm 3.0$ years. The average SNA was $82.42^{\circ}$, the average SNB was $76.38^{\circ}$, and the average ANB was $6.04^{\circ}$. Of the 30 patients with skeletal class III malocclusion, 17 were men and 13 were women, with a mean age $20.7 \pm 3.2$ years. The average SNA was $81.42^{\circ}$, the average $\mathrm{SNB}$ was $82.53^{\circ}$, and the average ANB was $-1.12^{\circ}$ (Table 3).

\section{Inter-group comparisons}

There were no significant difference in ' $D$ ', the anteriorposterior position of the mandibular foramen, and in ' $W$ ', the anterior-posterior width of the mandibular ramus among three groups. But there were significant difference in ' $\mathrm{V}$ ' and ' $\mathrm{P}$ ', the vertical position of the mandibular

Table 2 Items of measurement

\begin{tabular}{ll}
\hline W & Diameter of ramus \\
$\mathrm{D}$ & Distance of MF from a \\
$\mathrm{V}$ & Distance of MF from $\mathrm{s}$ \\
$\mathrm{P}$ & Distance of MF from I \\
$\mathrm{R}$ & Distance of Mandibular lower border from $\mathrm{s}$ \\
\hline
\end{tabular}

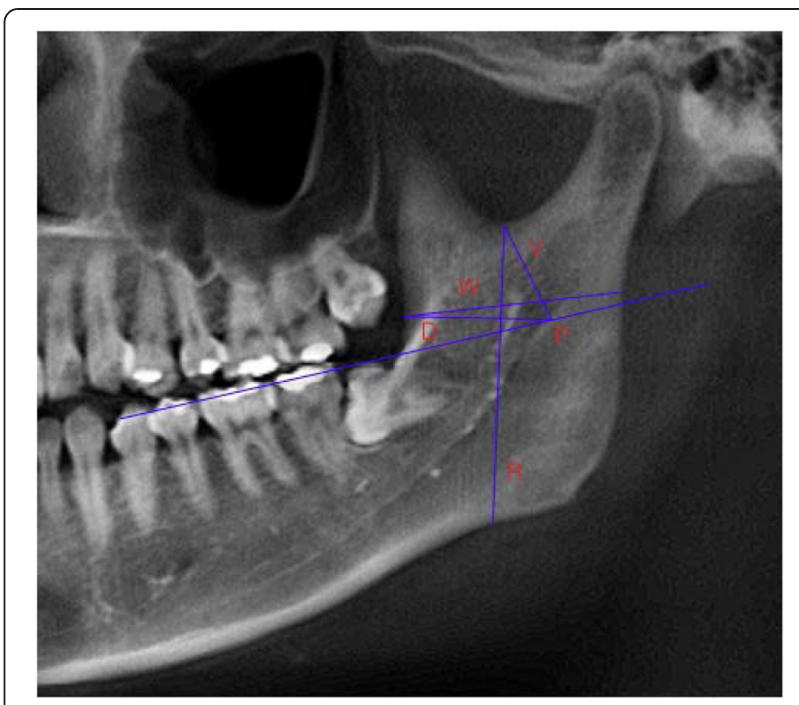

Fig. 2 Items of measurement

foramen $(p<0.05)$. The average $\mathrm{V}$ measurements (s-MF) were $21.59 \mathrm{~mm}$ in the normal occlusion group, $20.49 \mathrm{~mm}$ in the skeletal class II malocclusion group, and $18.77 \mathrm{~mm}$ in the skeletal class III malocclusion group. The average P measurements (l-MF) were $0.10 \mathrm{~mm}$ below the occlusal plane in the normal occlusion group, $0.03 \mathrm{~mm}$ below the occlusal plane in the skeletal class II malocclusion group, and $2.79 \mathrm{~mm}$ higher the occlusal plane in the skeletal class III malocclusion group. In addition, the average values of $R$ (s-mandible lower border), the length of the mandibular ramus, differed significantly among the three groups $(p<0.05): 48.38 \mathrm{~mm}$ in the normal occlusion group, $44.47 \mathrm{~mm}$ in the skeletal class II malocclusion group, and $52.94 \mathrm{~mm}$ in the skeletal class III malocclusion group. These results indicate progressive increases in the length of mandibular ramus from the skeletal class II malocclusion group to the normal occlusion group to the skeletal class III malocclusion group (Table 4).

\section{Gender comparisons within each group Comparisons between male patients for each group}

There were no significant difference in ' $\mathrm{D}$ ', the anteriorposterior position of the mandibular foramen, and in 'W', the anterior and posterior width of the mandibular ramus among three groups. But there were significant

Table 3 Sex, age of each group

\begin{tabular}{lllllll}
\hline Group & Sex & & Age & SNA & SNB & ANB \\
\hline A & Men: 13 & Women: 17 & $21.8(18 \sim 31)$ & $83.05^{\circ}$ & $80.22^{\circ}$ & $2.83^{\circ}$ \\
B & Men: 15 & Women: 25 & $22.2(18 \sim 30)$ & $82.42^{\circ}$ & $76.38^{\circ}$ & $6.04^{\circ}$ \\
C & Men: 17 & Women: 13 & $20.7(18 \sim 31)$ & $81.42^{\circ}$ & $82.53^{\circ}$ & $-1.12^{\circ}$ \\
\hline
\end{tabular}

A: Normal occlusion group

B: Class II malocclusion group

C: Class III malocclusion group 
Table 4 Comparison of normal occlusion, skeletal class II and III malocclusion group

\begin{tabular}{|c|c|c|c|c|c|c|}
\hline & \multirow[t]{2}{*}{ Group } & \multirow[t]{2}{*}{ Mean } & \multirow[t]{2}{*}{ SD } & \multicolumn{3}{|c|}{ Significance } \\
\hline & & & & $A-B$ & $A-C$ & $B-C$ \\
\hline \multirow[t]{3}{*}{ W } & $A$ & $31.6615 \mathrm{~mm}$ & \pm 2.75349 & & & \\
\hline & B & $31.6040 \mathrm{~mm}$ & \pm 2.19749 & & & \\
\hline & C & $31.1930 \mathrm{~mm}$ & \pm 2.87840 & & & \\
\hline \multirow[t]{3}{*}{ D } & A & $19.4077 \mathrm{~mm}$ & \pm 2.15708 & & & \\
\hline & B & $19.0080 \mathrm{~mm}$ & \pm 1.82927 & & & \\
\hline & C & $19.8488 \mathrm{~mm}$ & \pm 2.03664 & & & \\
\hline \multirow[t]{3}{*}{ V } & A & $21.5887 \mathrm{~mm}$ & \pm 2.45216 & & * & * \\
\hline & B & $20.4897 \mathrm{~mm}$ & \pm 2.86414 & & & \\
\hline & $C$ & $18.7697 \mathrm{~mm}$ & \pm 2.40634 & & & \\
\hline \multirow[t]{3}{*}{$P$} & A & $-0.0980 \mathrm{~mm}$ & \pm 2.97157 & & * & * \\
\hline & B & $-0.0333 \mathrm{~mm}$ & \pm 3.02146 & & & \\
\hline & C & $2.7877 \mathrm{~mm}$ & \pm 2.50825 & & & \\
\hline \multirow[t]{3}{*}{$\mathrm{R}$} & A & $48.3750 \mathrm{~mm}$ & \pm 5.77211 & * & * & * \\
\hline & B & $44.4713 \mathrm{~mm}$ & \pm 4.44070 & & & \\
\hline & C & $52.9430 \mathrm{~mm}$ & \pm 5.78652 & & & \\
\hline
\end{tabular}

A: Normal occlusion group

B: Class II malocclusion group

C: Class III malocclusion group

* significant at the level of $P<0.05$

difference in ' $V$ ' and ' $P$ ', the vertical position of the mandibular foramen $(p<0.05)$. With regard to the average $\mathrm{V}$ measurements (s-MF), there was a significant difference between the normal occlusion group and the other two groups: $22.29 \mathrm{~mm}$ in the normal occlusion group, $19.70 \mathrm{~mm}$ in the skeletal class II malocclusion group, and $19.62 \mathrm{~mm}$ in the skeletal class III malocclusion group. With regard to the average $\mathrm{P}$ measurements (1MF), there was a significant difference between the skeletal class III malocclusion group and the other two groups: $0.73 \mathrm{~mm}$ above the occlusal plane in the normal occlusion group, $0.70 \mathrm{~mm}$ above the occlusal plane in the skeletal class II malocclusion group, and $3.56 \mathrm{~mm}$ above the occlusal plane in the skeletal class III malocclusion group. In addition, with regard to the average $\mathrm{R}$ measurements (s-mandible lower border), the length of the mandibular ramus was $53.27 \mathrm{~mm}$ in the normal occlusion group, $47.02 \mathrm{~mm}$ in the skeletal class II malocclusion group, and $56.89 \mathrm{~mm}$ in the skeletal class III malocclusion group. The difference between the skeletal class II and III malocclusion groups was significant, and the length of mandibular ramus in the skeletal class III malocclusion group was relatively longer than in the other two groups (Table 5).

\section{Comparisons between female patients for each group}

There were no significant difference in ' $\mathrm{D}$ ', the anteriorposterior position of the mandibular foramen, and in 'W',
Table 5 Comparison of normal occlusion, skeletal class II and III malocclusion group (only men)

\begin{tabular}{|c|c|c|c|c|c|c|}
\hline & \multirow[t]{2}{*}{ Group } & \multirow[t]{2}{*}{ Mean } & \multirow[t]{2}{*}{ SD } & \multicolumn{3}{|c|}{ Significance } \\
\hline & & & & $A-B$ & $A-C$ & $B-C$ \\
\hline \multirow[t]{3}{*}{ W } & A & $31.9108 \mathrm{~mm}$ & \pm 2.94028 & & & \\
\hline & B & $32.3123 \mathrm{~mm}$ & \pm 2.42030 & & & \\
\hline & C & $31.9850 \mathrm{~mm}$ & \pm 2.44729 & & & \\
\hline \multirow[t]{3}{*}{ D } & A & $19.2100 \mathrm{~mm}$ & \pm 2.35720 & & & \\
\hline & B & $19.1659 \mathrm{~mm}$ & \pm 1.91019 & & & \\
\hline & C & $20.4659 \mathrm{~mm}$ & \pm 1.95319 & & & \\
\hline \multirow[t]{3}{*}{ V } & A & $22.2931 \mathrm{~mm}$ & \pm 2.36451 & * & * & \\
\hline & B & $19.6991 \mathrm{~mm}$ & \pm 3.63638 & & & \\
\hline & C & $19.6232 \mathrm{~mm}$ & \pm 2.32103 & & & \\
\hline \multirow[t]{3}{*}{ P } & A & $0.7277 \mathrm{~mm}$ & \pm 3.05969 & & $*$ & * \\
\hline & B & $0.7000 \mathrm{~mm}$ & \pm 3.46783 & & & \\
\hline & C & $3.5553 \mathrm{~mm}$ & \pm 2.46164 & & & \\
\hline \multirow[t]{3}{*}{$\mathrm{R}$} & A & $53.2700 \mathrm{~mm}$ & \pm 5.72731 & & & * \\
\hline & B & $47.0150 \mathrm{~mm}$ & \pm 5.06719 & & & \\
\hline & C & $56.8920 \mathrm{~mm}$ & \pm 3.65576 & & & \\
\hline
\end{tabular}

A: Normal occlusion group

B: Class II malocclusion group

C: Class III malocclusion group

* significant at the level of $P<0.05$

the anterior and posterior width of the mandibular ramus. However, there were significant differences in ' $\mathrm{V}$ ' and ' $\mathrm{P}$ ', the vertical position of the mandibular foramen, in the skeletal class III malocclusion group and the other two groups $(p<0.05)$. In the average $\mathrm{V}$ measurements (s-MF) were $21.05 \mathrm{~mm}$ in the normal occlusion group, $20.95 \mathrm{~mm}$ in the skeletal class II malocclusion group, and $18.31 \mathrm{~mm}$ in the skeletal class III malocclusion group. In the average P measurements (l-MF) were $0.73 \mathrm{~mm}$ below the occlusal plane in the normal occlusion group, $0.46 \mathrm{~mm}$ below the occlusal plane in the skeletal class II malocclusion group, and $1.78 \mathrm{~mm}$ above the occlusal plane in the skeletal class III malocclusion group. In addition, with regard to the average $\mathrm{R}$ measurements (s-mandible lower border), the length of the mandibular ramus was $47.15 \mathrm{~mm}$ in the normal occlusion group, $43.55 \mathrm{~mm}$ in the skeletal class II malocclusion group, and $48.99 \mathrm{~mm}$ in the skeletal class III malocclusion group. The difference was significant only between the skeletal class II and III malocclusion groups, and the length of the mandibular ramus was relatively longer in the skeletal class III malocclusion group (Table 6).

\section{Comparisons between men and women in the same group}

There was no significant differences in the anteriorposterior or vertical positions of the mandibular foramen, the anterior-posterior width of ramus, or the vertical length of the ramus in the normal occlusion group and in the 
Table 6 Comparison of normal occlusion, skeletal class II and III malocclusion group (only women)

\begin{tabular}{|c|c|c|c|c|c|c|}
\hline & \multirow[t]{2}{*}{ Group } & \multirow[t]{2}{*}{ Mean } & \multirow[t]{2}{*}{ SD } & \multicolumn{3}{|c|}{ Significance } \\
\hline & & & & $A-B$ & $A-C$ & $B-C$ \\
\hline \multirow[t]{3}{*}{ W } & $A$ & $31.4709 \mathrm{~mm}$ & \pm 2.63046 & & & \\
\hline & B & $31.1939 \mathrm{~mm}$ & \pm 1.97599 & & & \\
\hline & C & $30.1573 \mathrm{~mm}$ & \pm 3.11106 & & & \\
\hline \multirow[t]{3}{*}{ D } & A & $19.5588 \mathrm{~mm}$ & \pm 2.01378 & & & \\
\hline & B & $18.9166 \mathrm{~mm}$ & \pm 1.80043 & & & \\
\hline & C & $19.0419 \mathrm{~mm}$ & \pm 1.88635 & & & \\
\hline \multirow[t]{3}{*}{ V } & $A$ & $21.0500 \mathrm{~mm}$ & \pm 2.41356 & & * & * \\
\hline & B & $20.9474 \mathrm{~mm}$ & \pm 2.23361 & & & \\
\hline & C & $18.3073 \mathrm{~mm}$ & \pm 2.48235 & & & \\
\hline \multirow[t]{3}{*}{$P$} & A & $-0.7294 \mathrm{~mm}$ & \pm 2.78340 & & * & * \\
\hline & B & $-0.4579 \mathrm{~mm}$ & \pm 2.68832 & & & \\
\hline & C & $1.7838 \mathrm{~mm}$ & \pm 2.23594 & & & \\
\hline \multirow[t]{3}{*}{$\mathrm{R}$} & A & $47.1513 \mathrm{~mm}$ & \pm 5.25874 & & & * \\
\hline & B & $43.5464 \mathrm{~mm}$ & \pm 3.91307 & & & \\
\hline & C & 48.9940 mm & \pm 4.76117 & & & \\
\hline
\end{tabular}

A: Normal occlusion group

B: Class II malocclusion group

C: Class III malocclusion group

* significant at the level of $P<0.05$

skeletal class II malocclusion group (Tables 7, 8). However, in the skeletal class III malocclusion group, there were significant differences between the men and women in the average values of $\mathrm{D}$ (the anterior-posterior position of the mandibular foramen), W (the anterior-posterior width of the mandibular ramus), $\mathrm{P}$ (the vertical position of the mandibular foramen), and $\mathrm{R}$ (the length of the mandibular ramus) $(p<0.05)$. The average $\mathrm{D}(\mathrm{a}-\mathrm{MF})$ measured $20.47 \mathrm{~mm}$ in the men and $19.04 \mathrm{~mm}$ in the women. The average W (a-mandible posterior border) was $31.99 \mathrm{~mm}$ in the men and $30.16 \mathrm{~mm}$ in the women. The average P (1-

Table 7 Comparison of men and women (in normal occlusion group)

\begin{tabular}{|c|c|c|c|c|}
\hline & Group & Mean & SD & Significance \\
\hline \multirow[t]{2}{*}{ W } & Men & $31.9108 \mathrm{~mm}$ & \pm 2.94028 & \\
\hline & Women & $31.4709 \mathrm{~mm}$ & \pm 2.63046 & \\
\hline \multirow[t]{2}{*}{ D } & Men & $19.2100 \mathrm{~mm}$ & \pm 2.35720 & \\
\hline & Women & $19.5588 \mathrm{~mm}$ & \pm 2.01378 & \\
\hline \multirow[t]{2}{*}{ V } & Men & $22.2931 \mathrm{~mm}$ & \pm 2.36451 & \\
\hline & Women & $21.0500 \mathrm{~mm}$ & \pm 2.41356 & \\
\hline \multirow[t]{2}{*}{$P$} & Men & $0.7277 \mathrm{~mm}$ & \pm 3.05969 & \\
\hline & Women & $-0.7294 \mathrm{~mm}$ & \pm 2.78340 & \\
\hline \multirow[t]{2}{*}{$R$} & Men & $53.2700 \mathrm{~mm}$ & \pm 5.72731 & \\
\hline & Women & $47.1513 \mathrm{~mm}$ & \pm 5.25874 & \\
\hline
\end{tabular}

* significant at the level of $P<0.05$
Table 8 Comparison of men and women (in skeletal class II malocclusion group)

\begin{tabular}{|c|c|c|c|c|}
\hline & Group & Mean & SD & Significance \\
\hline \multirow[t]{2}{*}{ W } & Men & $32.3123 \mathrm{~mm}$ & \pm 2.42030 & \\
\hline & Women & $31.1939 \mathrm{~mm}$ & \pm 1.97599 & \\
\hline \multirow[t]{2}{*}{ D } & Men & $19.1659 \mathrm{~mm}$ & \pm 1.91019 & \\
\hline & Women & $18.9166 \mathrm{~mm}$ & \pm 1.80043 & \\
\hline \multirow[t]{2}{*}{ V } & Men & $19.6991 \mathrm{~mm}$ & \pm 3.63638 & \\
\hline & Women & $20.9474 \mathrm{~mm}$ & \pm 2.23361 & \\
\hline \multirow[t]{2}{*}{$P$} & Men & $0.7000 \mathrm{~mm}$ & \pm 3.46783 & \\
\hline & Women & $-0.4579 \mathrm{~mm}$ & \pm 2.68832 & \\
\hline \multirow[t]{2}{*}{$\mathrm{R}$} & Men & $47.0150 \mathrm{~mm}$ & \pm 5.06719 & \\
\hline & Women & $43.5464 \mathrm{~mm}$ & \pm 3.91307 & \\
\hline
\end{tabular}

* significant at the level of $P<0.05$

MF) was $3.56 \mathrm{~mm}$ above the occlusal plane in the men and $1.78 \mathrm{~mm}$ above the occlusal plane in the women. The average R (s-mandible lower border) was $56.89 \mathrm{~mm}$ in the men and $48.99 \mathrm{~mm}$ in the women (Table 9).

\section{Intergender comparisons within the total study group}

There was no significance difference between the men and the women with respect to $\mathrm{D}$ (the anterior-posterior position of the mandibular foramen), yet there were significant differences in W (the anterior-posterior width of the mandibular ramus), $\mathrm{P}$ (the vertical position of the mandibular foramen), and $\mathrm{R}$ (the length of mandibular ramus) $(p<0.05)$. The average $\mathrm{W}$ (a-mandible posterior border) was $32.05 \mathrm{~mm}$ in the men and $31.02 \mathrm{~mm}$ in the women. The average P (l-MF) was $1.89 \mathrm{~mm}$ above the occlusal plane in the men and $0.04 \mathrm{~mm}$ above the occlusal plane in the women. The average $\mathrm{R}$ (s-mandible lower border) was $52.64 \mathrm{~mm}$ in the men and $45.88 \mathrm{~mm}$ in the women (Table 10).

Table 9 Comparison of men and women (in skeletal class III malocclusion group)

\begin{tabular}{lllll}
\hline & Group & Mean & SD & Significance \\
\hline W & Men & $31.9850 \mathrm{~mm}$ & \pm 2.44729 & $*$ \\
& Women & $30.1573 \mathrm{~mm}$ & \pm 3.11106 & \\
D & Men & $20.4659 \mathrm{~mm}$ & \pm 1.95319 & $*$ \\
& Women & $19.0419 \mathrm{~mm}$ & \pm 1.88635 & \\
V & Men & $19.1232 \mathrm{~mm}$ & \pm 2.32103 & \\
& Women & $18.3073 \mathrm{~mm}$ & \pm 2.48235 & \\
P & Men & $3.5553 \mathrm{~mm}$ & \pm 2.46164 & $*$ \\
& Women & $1.7838 \mathrm{~mm}$ & \pm 2.23594 & \\
R & Men & $56.8920 \mathrm{~mm}$ & \pm 3.65576 & $*$ \\
& Women & $48.9940 \mathrm{~mm}$ & \pm 4.76117 & \\
\hline
\end{tabular}

* significant at the level of $P<0.05$ 
Table 10 Comparison of men and women

\begin{tabular}{lllll}
\hline & Group & Mean & SD & Significance \\
\hline W & Men & $32.0493 \mathrm{~mm}$ & \pm 2.57948 & $*$ \\
& Women & $31.0150 \mathrm{~mm}$ & \pm 2.57302 & \\
D & Men & $19.7189 \mathrm{~mm}$ & \pm 2.14839 & \\
& Women & $19.1727 \mathrm{~mm}$ & \pm 1.90151 & \\
V & Men & $20.2828 \mathrm{~mm}$ & \pm 3.05004 & \\
& Women & $20.2826 \mathrm{~mm}$ & \pm 2.62647 & \\
P & Men & $1.8927 \mathrm{~mm}$ & \pm 3.23393 & $*$ \\
& Women & $0.0427 \mathrm{~mm}$ & \pm 2.79296 & \\
R & Men & $52.6418 \mathrm{~mm}$ & \pm 6.30166 & $*$ \\
& Women & $45.8829 \mathrm{~mm}$ & \pm 5.01705 & \\
\hline
\end{tabular}

* significant at the level of $P<0.05$

Comparison between division 1 and division 2 subsets of patients with skeletal class II malocclusion group

There were no significant differences between the division 1 and division 2 patients with respect to the anterior, posterior, or vertical positions of the mandibular foramen or the width and length of the mandibular ramus (Table 11).

\section{Discussion}

The mandibular foramen and the mandibular canal form during the process of intramembranous ossification of the mandibular ramus and the body of mandible. During the 24th week of the embryonic stage, a groove forms that contains the nerves and blood vessels, and the shapes of the mandibular foramen and canal completed as ossification progresses [12]. Starting from the mandibular foramen within the ramus, the mandibular canal containing the inferior alveolar nerve and blood vessels descends in antero-inferior direction and then runs horizontally once it reaches the molar area of the mandible body. At this point the canal splits into the incisive canal, which runs from the premolar to the anterior mandible, and the mental canal,

Table 11 Comparision of division 1 and 2 (skeletal class II malocclusion)

\begin{tabular}{|c|c|c|c|c|}
\hline & Group & Mean & SD & Significance \\
\hline \multirow[t]{2}{*}{ W } & Division 1 & $31.6522 \mathrm{~mm}$ & \pm 2.21051 & \\
\hline & Division 2 & $31.5075 \mathrm{~mm}$ & \pm 2.22499 & \\
\hline \multirow[t]{2}{*}{ D } & Division 1 & $19.1013 \mathrm{~mm}$ & \pm 1.89594 & \\
\hline & Division 2 & $18.8215 \mathrm{~mm}$ & \pm 1.71978 & \\
\hline \multirow[t]{2}{*}{ V } & Division 1 & $19.9697 \mathrm{~mm}$ & \pm 2.97195 & \\
\hline & Division 2 & $20.5795 \mathrm{~mm}$ & \pm 2.52002 & \\
\hline \multirow[t]{2}{*}{ P } & Division 1 & $-0.1140 \mathrm{~mm}$ & \pm 2.83028 & \\
\hline & Division 2 & $0.1280 \mathrm{~mm}$ & \pm 2.22499 & \\
\hline \multirow[t]{2}{*}{$\mathrm{R}$} & Division 1 & $44.2195 \mathrm{~mm}$ & \pm 4.35233 & \\
\hline & Division 2 & $44.9750 \mathrm{~mm}$ & \pm 4.80920 & \\
\hline
\end{tabular}

* significant at the level of $P<0.05$ which runs in a postero-superior direction and opens below the apical root of the second premolar, becoming the mental foramen [13].

Although inferior alveolar nerve block is frequently used as a local anesthetic method for restorative treatment and surgical treatment of mandibular molars $[14,15]$, Malamed et al. [16] reported that this method is associated with a high clinical failure rate of up to 15 to $20 \%$. This can be explained by the fact that the positions of the mandibular ramus and foramen vary widely from person to person [14]. In addition, if surgeon fails to identify the exact anatomical position of the mandibular foramen during orthognathic surgery, complications may ensue, such as damage to the inferior alveolar nerve or blood vessels. Thus, the position of the foramen serves as a critical anatomical reference point for reducing the risk of complications and for the success of inferior alveolar nerve block anesthesia [3].

The position of the mandibular foramen is known to vary with age. According to Hwang et al. [17], the mandibular foramen is located below the occlusal plane during the deciduous dentition stage and is positioned at $4.14 \mathrm{~mm}$ above the occlusal plane in adults. Kanno et al. [18] have reported that the mandibular lingula can be seen at $6 \mathrm{~mm}$ above the occlusal plane in children ages 7 to 8 and at $10 \mathrm{~mm}$ above the occlusal plane in children ages 9 to 10 . In addition, during deciduous dentition the anterior-posterior position of the foramen is in center of the ramal surface but will then move slightly toward the back [19]. To avoid the possible effect of this positional change, in this study, only patients who were 18 to 31 years of age were included.

It is critically important to accurately identify the position of the mandibular foramen in the clinical setting. Radiography makes this possible in a non-invasive manner, and panoramic radiography is the most commonly used technique, because it enables the practitioner to simultaneously observe the teeth, jaw and temporomandibular joint [20-22]. Although panoramic radiography is cost-effective and easy to handle, magnification varies depending on camera type [1], which may result in distorted or deformed images if the patient's jaw bone is not positioned correctly in the focal trough. CT enables a three-dimensional evaluation by the reconstruction of images, resulting in better precision. With the images obtained by means of panoramic radiography, the probability of identifying the incisive canal in the mandible in two different studies was $2.7 \%$ [23] to about $15 \%$ [20]. In comparison, three studies evaluated $\mathrm{CT}$ images and reported corresponding values to be $83 \%$ [24] to $100 \%$ $[25,26]$. Although CT offers many advantages, it is expensive and difficult to use in the clinical setting and is therefore employed less often. In contrast, when compared with conventional CT, CBCT requires a lower dose of radiation, is easier to control, and minimizes metal artifact and is therefore used more frequently in 
clinical setting. For these reasons, this study relied on the more accessible CBCT to analyze the position of the mandibular foramen.

In their study comparing the anterior-posterior position of the mandibular foramen, da Fontoura et al. [9] noted that the foramen is positioned in the middle third of ramus. In addition, Trost et al. [10] found that the mandibular foramen did not exist in the region of the upper and posterior third of the ramus. In their study of the distance from the anterior edge of the ramus to the foramen in a horizontal relationship, Afsar et al. [27] analyzed radiographs and found this distance to be an average of $20.20 \mathrm{~mm}$. In their analysis of 40 Taiwanese patients, $\mathrm{Yu}$ et al. [28] reported this distance to average $18.00 \mathrm{~mm}$ in the women and $19.30 \mathrm{~mm}$ in the men. In addition, Kaffe et al. [1] measured this distance as an average of $20.26 \mathrm{~mm}$ using panoramic radiography of dry mandibles.

In contrast, Seo et al. [11] in their examination of panoramic radiographs from Korean patients diagnosed with either normal occlusion or prognathism, compared the distance from the anterior edge of the ramus to the mandibular foramen and found it to be average of $24.48 \mathrm{~mm}$ in those with normal occlusion and $24.535 \mathrm{~mm}$ in those with prognathism. In this study using $\mathrm{CBCT}$, however, this distance was an average of $19.41 \mathrm{~mm}, 19.01 \mathrm{~mm}$, and $19.85 \mathrm{~mm}$ in the normal occlusion group, the skeletal class II malocclusion group, and the skeletal class III malocclusion group, respectively. Although these results were lower than those in the study by Seo et al. [11] and there was no significant difference among the three groups, when this distance compared in the male and female patients in the skeletal class III malocclusion group, it averaged $20.47 \mathrm{~mm}$ in the men and $19.04 \mathrm{~mm}$ in the womenthat is, $1.43 \mathrm{~mm}$ longer in the men-and the difference was statistically significant $(p<0.05)$. With regard to the horizontal width of ramus, the average values were $31.99 \mathrm{~mm}$ in the men and $30.16 \mathrm{~mm}$ in the women-that is, $1.83 \mathrm{~mm}$ longer in the men.

Lima et al. [29] compared the vertical position of the mandibular foramen and reported that the distance from mandibular notch to the foramen served as a critical reference point for identifying the position of the mandibular foramen during orthognathic surgery and thus gave it clinical importance. They reported an average distance of $27.70 \mathrm{~mm}$, whereas Gutierrez-Ventura et al. [30] reported an average distance of $17.44 \mathrm{~mm}$. In a report by $\mathrm{Yu}$ et al. [28], these values were $22.70 \mathrm{~mm}$ in their male patients and $20.50 \mathrm{~mm}$ in their female patients. In this study, the distance from the mandibular notch to the mandibular foramen was $21.59 \mathrm{~mm}$ in the normal occlusion group, $20.49 \mathrm{~mm}$ in the skeletal class II malocclusion group, and $18.77 \mathrm{~mm}$ in the skeletal class III malocclusion group. These values were similar to those reported in other studies, although the value was significantly lower in the skeletal class III malocclusion group.

In an analysis of the occlusal plane, the position of mandibular foramen was $0.10 \mathrm{~mm}$ below this plane in the normal occlusion group, $0.03 \mathrm{~mm}$ below this plane in the skeletal class II malocclusion group, and, significantly, $2.79 \mathrm{~mm}$ above the occlusal plane in the skeletal class III malocclusion group. These results were the same as those in a study conducted by Seo et al. [11].

The average vertical length of the mandibular ramus at about $2.89 \mathrm{~mm}$ above the occlusal plane. The average vertical length of the mandibular ramus was $48.38 \mathrm{~mm}$ in the normal occlusion group, $44.47 \mathrm{~mm}$ in the skeletal class II malocclusion group, and $52.94 \mathrm{~mm}$ in the skeletal class III malocclusion group, in whom it was the longest. This difference appears to be the reason for the difference in the vertical position of the mandibular foramen among the groups studied.

In addition, there were significant differences in the distance from the occlusal plane to the mandibular foramen in the intergender comparisons. Specifically, this distance averaged 1.89 and $0.04 \mathrm{~mm}$ in the men and women, respectively, or $1.85 \mathrm{~mm}$ greater in the male patients. The average vertical length of the ramus was $52.6 \mathrm{~mm}$ in the men and $45.88 \mathrm{~mm}$ in the women, or about $6.76 \mathrm{~mm}$ longer in the male patients. These results were consistent with those of a study by Indira et al. [31] and indicate that variations in the vertical length are due to differences in the length of the mandible ramus.

Until now, no other study has compared the position of the mandibular foramen among patients with normal occlusion, skeletal class II and III malocclusion. Here, $\mathrm{CBCT}$ images determined that the position of the foramen varies from person to person and is higher in patients with skeletal class III malocclusion. The intergender comparisons showed that the mandibular foramen is higher in men than in women. Thus, CBCT can most likely be used effectively to evaluate the position of the mandibular foramen prior to inferior alveolar nerve block anesthesia or orthognathic surgery. In addition, it will be useful to reconstruct images of the mandible obtained with $\mathrm{CBCT}$ to create three-dimensional images and then to compare the position of the mandibular foramen with the results of this study.

\section{Conclusions}

In this study, the position of the mandibular foramen was determined with use of $\mathrm{CBCT}$ and compared in patients with normal occlusion, skeletal class II and III malocclusion. The following is a summary of the results.

The anterior-posterior position of the mandibular foramen, as based on the deepest point on the anterior edge of the ramus, averaged $19.41 \mathrm{~mm}$ (men, $19.21 \mathrm{~mm}$; women, $19.59 \mathrm{~mm}$ ) in the normal occlusion group. It 
averaged $19.01 \mathrm{~mm}$ in the skeletal class II malocclusion group (men, $19.17 \mathrm{~mm}$; women, $18.92 \mathrm{~mm}$ ) and $19.85 \mathrm{~mm}$ in the skeletal class III malocclusion group (men, $20.47 \mathrm{~mm}$; women, $19.04 \mathrm{~mm}$ ), indicating no significant difference among the three groups. This distance in men was $1.43 \mathrm{~mm}$ longer than in the women for the skeletal class III malocclusion group, a finding that was statistically significant $(p<0.05)$.

The vertical position of the mandibular foramen, as based on the extension of the occlusal plane, averaged $-0.10 \mathrm{~mm}$ in the normal occlusion group (men, $0.73 \mathrm{~mm}$; women, $-0.72 \mathrm{~mm}$ ), $-0.03 \mathrm{~mm}$ in the skeletal class II malocclusion group (men, $0.70 \mathrm{~mm}$; women, $-0.46 \mathrm{~mm}$ ), and $2.79 \mathrm{~mm}$ in the skeletal class III malocclusion group (men, $3.56 \mathrm{~mm}$; women, $1.78 \mathrm{~mm}$ ), that is, it was higher (in both men and women) in the patients with skeletal class III malocclusion $(p<0.05)$. In addition, the mandibular foramen was positioned approximately $1.85 \mathrm{~mm}$ higher in the men than in the women $(p<0.05)$.

The full width of the mandibular ramus averaged $31.66 \mathrm{~mm}$ in the normal occlusion group (men, $31.91 \mathrm{~mm}$; women, $31.47 \mathrm{~mm}$ ), $31.60 \mathrm{~mm}$ in the skeletal class II malocclusion group (men, $32.31 \mathrm{~mm}$; women, $31.19 \mathrm{~mm}$ ), and $31.19 \mathrm{~mm}$ in the skeletal class III malocclusion group (men, $31.99 \mathrm{~mm}$; women, $30.16 \mathrm{~mm}$ ), indicating no significant difference between these three groups. This width was approximately $1.03 \mathrm{~mm}$ longer in the men than in the women, and the difference was statistically significant $(p<0.05)$.

The average length of the mandibular ramus was $48.38 \mathrm{~mm}$ in the normal occlusion group (men, $53.27 \mathrm{~mm}$; women, $47.15 \mathrm{~mm}$ ), $44.47 \mathrm{~mm}$ in the skeletal class II malocclusion group (men, $47.02 \mathrm{~mm}$; women, $43.55 \mathrm{~mm}$ ), and $52.94 \mathrm{~mm}$ in the skeletal class III malocclusion group (men, $56.89 \mathrm{~mm}$; women, $48.99 \mathrm{~mm}$ ). Thus, this length was greatest in the skeletal class III malocclusion group $(p<0.05)$ and was $7.9 \mathrm{~mm}$ longer in the men than in the women $(p<0.05)$.

When the skeletal class II malocclusion group division 1 and division 2 patients were compared, there were no significant differences in these measurements.

In this study, CBCT, which is now in widespread use, was chosen as the best method for analyzing the positional relationship of the mandibular foramen to surrounding structures. According to the results reported here, the position of the mandibular foramen varies from person to person, and in the skeletal class III malocclusion patients it was located higher than the position in the other two groups. More likely, this is because the length of ramus in the skeletal class III malocclusion group exceeds that in the other two groups.

\section{Competing interests}

The authors declare that they have no competing interests.

\section{Authors' contributions}

$\mathrm{H}$-SP participated in the design of study, acquisition, analysis and interpretation of data, and involved in drafting the manuscript. J-HL conceived of the study, and participated in its design and coordination and helped to draft the manuscript, revising it critically for important intellectual content, have given final approval of the version to be published. Both author read and approved the final manuscript.

\section{Acknowledgement}

This study was supported by the research fund of Dankook University in 2015.

Received: 3 July 2015 Accepted: 31 July 2015

Published online: 19 August 2015

\section{References}

1. Kaffe I, Ardekian L, Gelerenter I, Taicher S (1994) Location of the mandibular foramen in panoramic radiographs. Oral Surg Oral Med Oral Pathol 78(5):662-669

2. Hetson G, Share J, Frommer J, Kronman JH (1988) Statistical evaluation of the position of the mandibular foramen. Oral Surg Oral Med Oral Pathol 65(1):32-34

3. Yoshida T, Nagamine T, Kobayashi T, Michimi N, Nakajima T, Sasakura H et al (1989) Impairment of the inferior alveolar nerve after sagittal split osteotomy. J Craniomaxillofac Surg 17(6):271-277

4. Koong B (2010) Cone beam imaging: is this the ultimate imaging modality? Clin Oral Implants Res 21(11):1201-1208

5. Boeddinghaus R, Whyte A (2008) Current concepts in maxillofacial imaging. Eur J Radiol 66(3):396-418

6. Suomalainen A, Kiljunen T, Kaser Y, Peltola J, Kortesniemi M (2009) Dosimetry and image quality of four dental cone beam computed tomography scanners compared with multislice computed tomography scanners. Dentomaxillofac Radiol 38(6):367-378

7. Gupta J, Ali SP (2013) Cone beam computed tomography in oral implants. Natl J Maxillofac Surg 4(1):2-6

8. Alves N, Deana NF (2014) Morphometric study of mandibular foramen in macerated skulls to contribute to the development of sagittal split ramus osteotomy (SSRO) technique. Surg Radiol Anat 36(9):839-845

9. da Fontoura RA, Vasconcellos HA, Campos AE (2002) Morphologic basis for the intraoral vertical ramus osteotomy: anatomic and radiographic localization of the mandibular foramen. J Oral Maxillofac Surg 60(6):660-665

10. Trost O, Salignon V, Cheynel N, Malka G, Trouilloud P (2010) A simple method to locate mandibular foramen: preliminary radiological study. Surg Radiol Anat 32(10):927-931

11. Seo BS, Lee JH, Kim KW (2002) A comparative study on the location of the mandibular foramen in panoramic radiographs of normal occlusion and mandibular prognathism. J Korean Assoc Maxillofac Plast Reconstr Surg 24(3):244-251

12. Kjaer I, Keeling JW, Hansen BF (1999) The prenatal human cranium: normal and pathologic development. Munksgaard, Copenhagen

13. Carter RB, Keen EN (1971) The intramandibular course of the inferior alveolar nerve. J Anat 108(3):433-440

14. Madan GA, Madan SG, Madan AD (2002) Failure of inferior alveolar nerve block: exploring the alternatives. J Am Dent Assoc 133(7):843-846

15. Thangavelu K, Kannan R, Kumar NS, Rethish E, Sabitha S, Sayeeganesh N (2012) Significance of localization of mandibular foramen in an inferior alveolar nerve block. J Nat Sci Biol Med 3(2):156-160

16. Malamed SF (1997) Handbook of local anesthesia, 4th edn. Mosby, St. Louis, Mo, USA

17. Hwang TJ, Hsu SC, Huang QF, Guo MK (1990) Age changes in location of mandibular foramen. Chinese Dental Journal 9(3):98-103

18. Kanno CM, de Oliveira JA, Cannon M, Carvalho AA (2005) The mandibular lingula's position in children as a reference to inferior alveolar nerve block. J Dent Child 72(2):56-60

19. Kim HG, Yoon JH (1982) A study of the anteroposterior positional and radiographical measurement of the mandibular foramen of the Korean adult. J Korean Assoc Oral Maxillofac Surg 8(1):137-145

20. Jacobs R, Mraiwa N, Van Steenberghe D, Sanderink G, Quirynen M (2004) Appearance of the mandibular incisive canal on panoramic radiographs. Surg Radiol Anat 26(4):329-333 
21. Kuzmanovic DV, Payne AG, Kieser JA, Dias GJ (2003) Anterior loop of the mental nerve: a morphological and radiographic study. Clin Oral Implants Res 14(4):464-471

22. Akarslan ZZ, Erten H, Gungor K, Celik I (2003) Common errors on panoramic radiographs taken in a dental school. J Contemp Dent Pract 4(2):24-34

23. Romanos GE, Papadimitriou DE, Royer K, Stefanova-Stephens N, Salwan R, Malmström $\mathrm{H}$ et al (2012) The presence of the mandibular incisive canal: a panoramic radiographic examination. Implant Dent 21(3):202-206

24. Pires CA, Bissada NF, Becker JJ, Kanawati A, Landers MA (2012) Mandibular incisive canal: cone beam computed tomography. Clin Implant Dent Relat Res 14(1):67-73

25. Al-Ani O, Nambiar P, Ha KO, Ngeow WC (2013) Safe zone for bone harvesting from the interforaminal region of the mandible. Clin Oral Implants Res 24 Suppl A100:115-121

26. Jacobs R, Mraiwa N, van Steenberghe D, Gijbels F, Quirynen M (2002) Appearance, location, course, and morphology of the mandibular incisive canal: an assessment on spiral CT scan. Dentomaxillofac Radiol 31(5):322-327

27. Afsar A, Haas DA, Rossouw PE, Wood RE (1998) Radiographic localization of mandibular anesthesia landmarks. Oral Surg Oral Med Oral Pathol Oral Radiol Endod 86(2):234-241

28. Yu IH, Wong YK (2008) Evaluation of mandibular anatomy related to sagittal split ramus osteotomy using 3-dimensional computed tomography scan images. Int J Oral Maxillofac Surg 37(6):521-528

29. Lima DSC, Figuerêdo AA, Rocha EA, Costa VHMV, Castro MP, Silva RCP et al (2011) Estudo anatômico do forame mandibular e suas relações com pontos de referência do ramo da mandíbula. Rev Bras Cir Craniomaxilofac 14(2):91-96

30. Gutierrez-Ventura F, Vivanco YT (2014) Posición del agujero dentario inferior en la rama ascendente en huesos mandibulares secos de adultos. Revista Estomatológica Herediana 22(3):152-157

31. Indira AP, Markande A, David MP (2012) Mandibular ramus: an indicator for sex determination-a digital radiographic study. J Forensic Dent Sci 4(2):58-62

\section{Submit your manuscript to a SpringerOpen ${ }^{\circ}$ journal and benefit from:}

- Convenient online submission

- Rigorous peer review

- Immediate publication on acceptance

- Open access: articles freely available online

- High visibility within the field

- Retaining the copyright to your article

Submit your next manuscript at $\gg$ springeropen.com 